\title{
DIFFERENCES IN ENVIRONMENTAL RESPONSIBILITY BETWEEN MATERIALISTIC GROUPS
}

\author{
Michael A. CLUMP(1), Jessica M. BRANDEL ${ }^{1)}$ \\ ${ }^{1)}$ Boise State University, U. S. A. \\ and \\ Patrick J. SHARPE ${ }^{2)}$ \\ ${ }^{2)}$ United States Office of Personnel Management, U. S. A.
}

\begin{abstract}
The current study investigated the hypothesis that groups scoring High, Medium, and Low on Environmental Responsibility would have significantly different materialism profiles using the Materialism Values Scale and the Possession Satisfaction Inventory. Two hundred seventy-one undergraduate students completed the ECOSCALE and the measures of materialism for partial course credit. The results indicated that the three groups had significantly different materialism profiles. More specifically, the High Environmental Responsibility group scored significantly lower than the Low Environmental Responsibility group on the three subscales of the MVS and the PSI, and significantly lower than the Medium Environmental Responsibility group on two of the MVS subscales and the PSI. These results provide further support for the contention that the groups scoring differently on Environmental Responsibility differ in the way they view others and the environment as evidenced by the differences in their personality, values, and materialism profiles.
\end{abstract}

Key words: environmental, environmental responsibility, materialism, differences

Materialism involves the importance that one places on material possessions and the consumption of material goods. Materialism has been defined by Belk (1984) as "the importance a consumer attaches to worldly possessions" (p. 291), and "a set of centrally held beliefs about the importance of possession's in one's life" by Richins and Dawson (1992, p. 308). From these two separate definitions of materialism, it is easy to abstract that materialism is focused on how important possessions are to an individual, either from Belk's personality standpoint or Richins and Dawson's values perspective. Consequently, the objects a consumer values indicate a substantial amount of information about the individual because these objects can be considered an extension of an individual's self or identity (Belk, 1988). "A man whose most valued possessions are a Bible and his wedding ring probably differs in many ways from one who cares deeply about his snowmobile and hunting rifles. In a sense, the objects someone values are a window into that person's inner self' (Richins, 1994, p. 522).

Given that materialism is based on a focus on possessions which are very important

Address correspondence and reprint requests to: Michael A. Clump, Department of Psychology, Boise State University, 1910 University Dr., Boise, ID 83725-1715, USA (mclump@boisestate.edu). 
to an individual's life, life satisfaction/subjective well-being (Belk, 1984; Dawson \& Bamossy, 1991; La Barbera \& Gürhan, 1997; Richins \& Dawson, 1992), income satisfaction (Richins, 1987), locus-of-control (Hunt, Kernan, Chatterjee, \& Florsheim, 1990), social anxiety and envy (Schroeder \& Dugal, 1995), and sense of accomplishment (Richins \& Dawson, 1992), it would seem that materialism would affect how people view and interact with the environment. In a study examining the motives people have to conserve natural resources, DeYoung (1985-1986) found that individuals who scored high on materialism were significantly lower in intrinsic motivation (altruistic reasons for conservation), recycling and reusing behaviors, and frugality and participation than those scoring low on materialism. Tashchian, Slama, and Tashchian (1984) in their quest to measure materialism developed the Belief in Material Growth Scale, which was based on the belief that material growth was one of the three important determinants of attitudes toward energy conservation. Consequently, those who believe in material growth view energy conservation efforts as created to work against them personally, and thus these individuals score lower on environmental concern.

This study examined differences between those individuals who scored High on a measure of environmental responsibility to those who scored Medium, and Low on environmental responsibility. We expected that the group that scored High on environmental responsibility would score significantly lower on multiple measures of materialism.

\section{METHOD}

\section{Participants:}

Two hundred seventy-one undergraduate students (187 females and 84 males) from a large western American university participated in this study for partial course credit. A total of 31 participants were removed as a result of missing or incomplete data. The age of the participants ranged from 18 to 50 , with a mean age of $21.65(S D=5.94)$. Males and females in the current study did not differ in their scores on the ECOSCALE, $F(1,242)=1.32, n s$, consequently, their data were collapsed for further analyses.

Instruments:

ECOSCALE. Stone, Barnes, \& Montgomery (1995) designed the ECOSCALE to determine the environmental responsibility of consumers. This scale contains 31 items separated into two sections. The first section, which is composed of 22 items, examines the beliefs and attitudes of the participant concerning the environment using a 5-point Likert scale ranging from 1 (strongly disagree) to 5 (strongly agree). The second section, which is composed of 9 items, determines the frequency with which the respondent is involved in behaviors associated with environmental concern using a 5-point Likert scale with 1 (never) and 5 (always) as its anchors. The ECOSCALE is composed of seven factors labeled Opinions and Beliefs, Awareness, Willingness to Act, Attitude, Action Taken, Ability to Act, and Knowledge. An example of an item from the Opinions and Beliefs factor is, "The earth's resources are infinite and should be used to the fullest to increase the human standard of living" (reverse scored). "The amount of energy I use does not affect the environment to any significant degree" (reversed scored) is an example of an item from the Awareness subscale. "I have started or joined consumer boycott programs aimed at companies that produce excess pollution" and "There is nothing the average citizen can do to help stop environmental pollution" (reverse scored), are example items from the Willingness to Act and Attitude subscales, respectively. An item from the Action Taken subscale is "I have my engine tuned to help stop unwanted air pollution". Example items from the Ability to Act and Knowledge subscales are "I do not purchase products that are 
known to cause pollution" and "Acid rain only affects Canada" (reverse scored), respectively.

Material Values Scale. The 18-item Material Values Scale (MVS) was developed by Richins and Dawson (1992) to assess materialism from a values perspective. This instrument is composed of the three subscales of Centrality ( 7 items), Happiness (5 items), and Success (6 items), and it uses a 5 -point Likert scale with 1 (strongly disagree) and 5 (strongly agree) as anchors. The Centrality subscale assesses the extent to which an individual places possessions and their acquisition at the center of life. "I like a lot of luxury in life", is an example of an item from this subscale. An example of an item from the Happiness subscale, which is focused on assessing the notion that possessions are essential to satisfaction and well-being in life, is "I'd be happier if I could afford to buy more things". Finally, the Success subscale is based on the idea that materialists judge success by the number and quality of material possessions accumulated. An example item from the Success subscale is "I admire people who own expensive homes, cars, and clothes".

Possession Satisfaction Index. Scott and Lundstrom (1990) developed the Possession Satisfaction Index (PSI) to measure the degree with which possessions and the means to acquire possessions bring happiness to an individual. It is composed of 20 items assessing various aspects of satisfaction resulting from possessions and money and uses a 5-point Likert scale ranging from 1 (strongly disagree) to 5 (strongly agree). An example item from the PSI is "The more I have the better I feel" (Scott \& Lundstrom, 1990, p. 102).

Procedures:

The participants who scored in the bottom $33.3 \%$ of the frequency distribution of scores on the ECOSCALE were classified as the Low Environmental Responsibility group, those in the middle $33.33 \%$ of the frequency distribution were identified as the Medium Environmental Responsibility group, and those who scored in the top $33.3 \%$ of the distribution were identified as the High Environmental Responsibility group. Multivariate analysis of variance and univariate analyses of variance were computed for the three groups using the MVS subscales and the PSI scale as dependent variables.

\section{RESULTS}

Stone et al. (1995) reported a Cronbach's alpha of .93 for the total score of the ECOSCALE, which is slightly higher than the Cronbach's alpha of .80 for the current study. The reduction in $\alpha$ for the present study may have been a result of the sample differences between the current sample, which consisted of only psychology students, and Stone et al.'s sample which consisted of graduate students and business and pharmacy

Table 1. Intercorrelations of the Subscales of the ECOSCALE

\begin{tabular}{|c|c|c|c|c|c|c|}
\hline Subscale & $\begin{array}{l}\text { Opinions and } \\
\text { Beliefs }\end{array}$ & Awareness & $\begin{array}{l}\text { Willingness } \\
\text { to Act }\end{array}$ & Attitude & Action Taken & $\begin{array}{l}\text { Ability } \\
\text { to Act }\end{array}$ \\
\hline Awareness & $.36 * * *$ & & & & & \\
\hline Willingness to Act & $.34 * * *$ & $.33 * * *$ & & & & \\
\hline Attitude & $.38 * * *$ & $.29 * * *$ & $.25 * * *$ & & & \\
\hline Action Taken & $.31 * * *$ & $.22 * *$ & $.38 * * *$ & $.32 * * *$ & & \\
\hline Ability to Act & $.38 * * *$ & $.3 * * *$ & $.40 * * *$ & $.29 * * *$ & $.51 * * *$ & \\
\hline Knowledge & $.43 * * *$ & $.19^{* *}$ & $.31 * * *$ & $.38 * * *$ & $.43 * * *$ & $.41 * * *$ \\
\hline
\end{tabular}

Note: $n=271,{ }^{*} p<.05, * * p<.01, * * * p<.001$ 
Table 2. Intercorrelations of Subscales of the MVS

\begin{tabular}{lcc}
\hline Subscale & Success & Centrality \\
\hline Success & & \\
Centrality & $.60 * * *$ & \\
Happiness & $.53 * * *$ & $.42 * * *$ \\
\hline Note $: n=271, * p<.05, * * p<.01, * * * p<.001$ &
\end{tabular}

Table 3. Means and Standard Deviations for Environmental Responsibility groups on the Multiple Measures of Materialism

students. Many of the subscales of the ECOSCALE were significantly correlated and the correlations in the present study were similar to those found by Stone et al. (see Table 1 for the intercorrelations of the ECOSCALE's subscales).

The Cronbach's alphas for the MVS total scale in the current study was .87, the MVS Success subscale was .78, the MVS Centrality subscale was .73, and the MVS Happiness subscale was .75 . The internal consistencies for the current study are similar to those reported by Richins and Dawson (1992). The subscales of the MVS were highly intercorrelated for the current study (see Table 2), which are similar to those reported by Chatterjee and Hunt (1996), ranging from .42 between the Happiness and Centrality subscales to .60 between the Success and Centrality subscales. The internal consistency of the PSI in the current study, .78, was similar to value that Scott and Lundstrom (1990) originally found for the PSI.

Table 3 presents the means and standard deviations of the three groups on the MVS subscales and the PSI. The data indicated that the average materialism profiles of the three groups were significantly different, Wilk's $\lambda=.93 ; F(8,460)=2.30, p<.05$. More specifically, the three groups were found to be significantly different on the MVS Success subscale, $F(2,233)=5.03, p<.01$, MVS Centrality subscale, $F(2,233)=3.37, p<.05$, and the PSI, $F(2,233)=8.72, p<.001$. 
To better understand where the differences between the three groups occurred, we compared the High Environmental Responsibility group to both the Low Responsibility group and the Medium Environmental Responsibility group, and the Medium Environmental Responsibility group to the Low Environmental Responsibility group. The data indicated that the average materialism profiles of the High and Low Environmental Responsibility groups were significantly different, Wilk's $\lambda=.90 ; F(4,153)=4.60, p<.01$. The High Environmental Responsibility group had significantly lower mean scores on the MVS Success subscale, $F(1,156)=9.22, p<.01$, the MVS Centrality subscale, $F(1$, $156)=5.93, p<.05$, the MVS Happiness subscale, $F(1,156)=4.98, p<.05$, and the PSI, $F(1$, 156) $=16.09, p<.001$. The mean difference in materialism profiles for the High Environmental Responsibility and the Medium Environmental Responsibility group approached significance, Wilk's $\lambda=.94 ; F(4,154)=2.33, p=.06$. The High Environmental Responsibility had significantly lower mean scores on the MVS Success subscale, $F(1$, $157)=5.28, p<.05$, MVS Centrality subscale, $F(1,157)=5.21, p<.05$, and the PSI, $F(1$, $157)=8.21, p<.01$. There was no significant difference between the groups on the MVS Happiness subscale, $F(1,157)=1.72, n s$. Neither the multivariate analysis of variance, Wilk's $\lambda=.99 ; F(4,150)=.48, n s$, comparing materialism profile of the Low Environmental Responsibility group to the Medium Environmental Responsibility group nor the subsequent ANOVAs for the MVS Success subscale, $F(1,153)=.78, n s$, MVS Centrality subscale, $F(1,153)=.07$, $n s$, MVS Happiness subscale, $F(1,153)=.62$, $n s$, or PSI, $F(1,153)=1.57, n s$, were significant.

\section{DISCUSSION}

The group scoring High on Environmental Responsibility was expected to score lower on the measures of materialism, since it has been found that individuals who score high in materialism pursue a life of material complexity marked by positive attitudes toward industrial growth, a reliance on technology to solve problems, and a lack of concern for nature and the environment (Richins \& Dawson, 1992). Consequently, we expected that those individuals who did not score high on environmental responsibility would be more focused on material entities, and their gain, and only using resources for themselves, instead of the utilization of resources for the good of others.

Based on the data, there was support for the expectation that the group scoring High on Environmental Responsibility would score significantly lower on these multiple measures of materialism. The High Environmental Responsibility scored significantly lower than the Low Environmental Responsibility group on all of the measures of materialism, and significantly lower than the Medium Environmental Responsibility group on nearly all of the measures of materialism. Our findings that there were differences between the groups scoring High and Medium or Low on environmental responsibility is in line with Iwata's (1995) research that found there was a negative correlation between scores on a proenvironmentalism attitude scale and a 6-item materialism scale he developed for the study. 
It has been previously found that the groups scoring High and Low on Environmental Responsibility differ on both their value profiles (Clump, Ramanaiah, \& Sharpe, 2002) and personality profiles (Ramanaiah, Clump, \& Sharpe, 2000). In fact, it appears that the group scoring higher on environmental responsibility is actively concerned about the welfare of others, and thus they focus on preserving and protecting this welfare instead of controlling and dominating natural resources that sustain life. One important way of preserving and protecting the welfare of others is by being concerned about the environment and making sure that one is responsibly taking care of the environment.

Clump et al. (2002) suggested that a profile of the individuals who score highly on Environmental Responsibility has begun to be developed. We concur and feel that more of the pieces of this profile have been determined. Those individuals who score High on Environmental concern appear to perceive their actions and the environment in a different perspective than those who score Low on Environmental Responsibility. These individuals who score high on environmental responsibility realize the importance of helping and protecting others. They also are less likely to be focused on coveting and exploiting resources for their personal gain; and instead, they realize that new ideas should be tried with regard to our depleting environmental resources that will help provide for others, such as Iwata's (1990) anti-pollution purchasing behavior.

\section{REFERENCES}

Belk, R. W. 1984. Three scales to measure constructs related to materialism: Reliability, validity, and relationships to measures of happiness. In T. Kinnear (Ed.), Advances in Consumer Research, Vol. 11 (pp. 291-297). Provo, UT: Association for Consumer Research.

Belk, R. W. 1988. Possessions and the extended self. Journal of Consumer Research, 15, 139-168.

Chatterjee, A., \& Hunt, J. M. 1996. Self-monitoring as a personality correlate of materialism: An investigation of related cognitive orientation. Psychological Reports, 79, 523-528.

Clump, M., Ramanaiah, N. V., \& Sharpe, J. P. 2002. Value differences between environmentally responsible people and non-environmentally responsible people. Psychological Reports, 90, 1174-1178.

Dawson, S., \& Bamossy, G. 1991. If "we are what we have", what are we when we don't have? An exploratory study of materialism among expatriate Americans. Journal of Social Behavior and Personality, 6, 363-384.

DeYoung, R. 1985-1986. Encouraging environmentally appropriate behavior: The role of intrinsic motivation. Journal of Environmental Systems, 15, 281-292.

Hunt, J. M., Kernan, J. B., Chatterjee, A., \& Florsheim, R. A. 1990. Locus of control as a personality correlate of materialism: An empirical note. Psychological Reports, 67, 1101-1102.

Iwata, O. 1990. Relationships of proenvironmental attitudes to wildernism-urbanism and pro-preservation attitudes toward historical heritages. Psychologia, 33, 203-211.

Iwata, O. 1995. Relationships of proenvironmental attitudes with materialism and its associated attitudes toward money. Psychologia, 38, 252-257.

La Barbera, P. A., \& Gürhan, Z. 1997. The role of materialism, religiosity, and demographics in subjective well-being. Psychology and Marketing, 14, 71-97.

Ramanaiah, N. V., Clump, M., \& Sharpe, J. P. 2000. Personality profiles of environmentally responsible groups. Psychological Reports, 87, 176-178.

Richins, M. L. 1987. Media, materialism, and human happiness. In M. Wallendorf and P. Anderson (Eds.), Advances in Consumer Research, Vol. 14 (pp. 169-175). Provo, UT: Association for Consumer 
Research.

Richins, M. L. 1994. Special possessions and the expression of material values. Journal of Consumer Research, 21, 522-533.

Richins, M. L., \& Dawson, S. 1992. A consumer values orientation for materialism and its measurement: Scale development and validation. Journal of Consumer Research, 19, 303-316.

Schroeder, J. E., \& Dugal, S. S. 1995. Psychological correlates of the materialism construct. Journal of Social Behavior and Personality, 10, 243-253.

Scott, C., \& Lundstrom, W. J. 1990. Dimensions of possession satisfaction: A preliminary analysis. Journal of Satisfaction, Dissatisfaction, and Complaining Behavior, 3, 100-104.

Stone, G., Barnes, J. H., \& Montgomery, C. 1995. ECOSCALE: A scale for the measurement of environmentally responsible consumers. Psychology and Marketing, 12, 595-612.

Tashchian, A., Slama, M. E., \& Tashchian, R. 1984. Measuring attitudes toward energy conservation: Cynicism, belief in material growth, and faith in technology. Journal of Public Policy and Marketing, 3, 143-148. 